\title{
Tipologia Espacial Como Uma Instância dos Layouts Urbanos
}

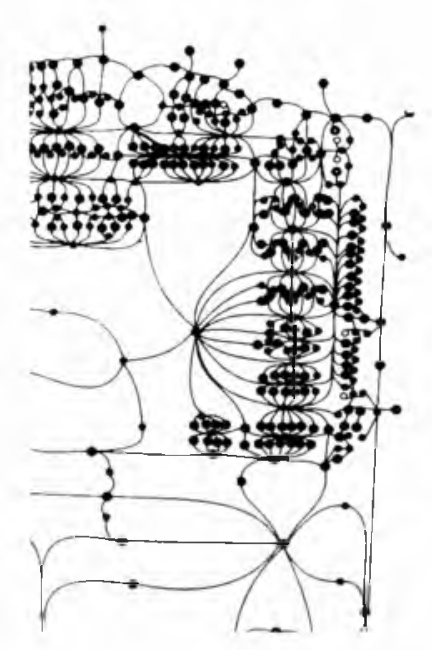

Professor do Departamento de Urbanismo da Faculdade de Arquitetura e Urbanismo da Universidade Federal do Rio Grande do Sul-UFRGS e do Programa de Pós-Graduação em Planejamento Urbano e Regional - PROPUR/UFRGS
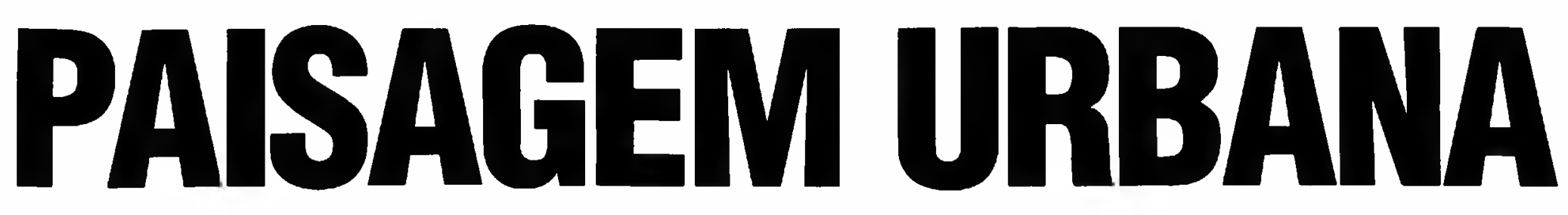
O presente trabalho tem como objetivo discutir layouts urbanos a partir de propriedades locais dos espaços, examinando como estes espaços podem ser descritos enquanto tipos (Hillier, 1997), segundo condições particulares de movimento e controle possiveis, a partir de cada tipo identificado. A importância dessa possibilidade de exame do espaço urbano fica evidenciada pela análise da tipologia espacial proposta para dois conjuntos residenciais de Porto Alegre/RS, de padrão semelhante, mas com propostas de projetos diferenciados. Observa-se, nas transformações implementadas

Lل pela população desses conjuntos, que os aspecțos de tipologia espacial são genotípicos para os conjuntos estudados e comparecem como aspectos de projeto que são cruciais para as possibilidades de uso e ocupação do espaço urbano por parte dos moradores.

This paper aims to analyse urban layouts according to local properties of space, trying to describe these local space as types (Hillier, 1997), taking into account the way movement and space control can occur in any of these types of spaces. The relevance of this study can be understood through the analysis of the space typology of two different housing estates built in Porto Alegre/RS with different design approaches and occupied by people with similar income. It's possible to observe that space typology seems to be a genotypical aspect of these urban layouts when we look at the outcome of the process of spatial transformation held in the estates overtime. At the same time, it seems that the way space typology is used to designing housing estates is a crucial aspect of the potential use of urban space.
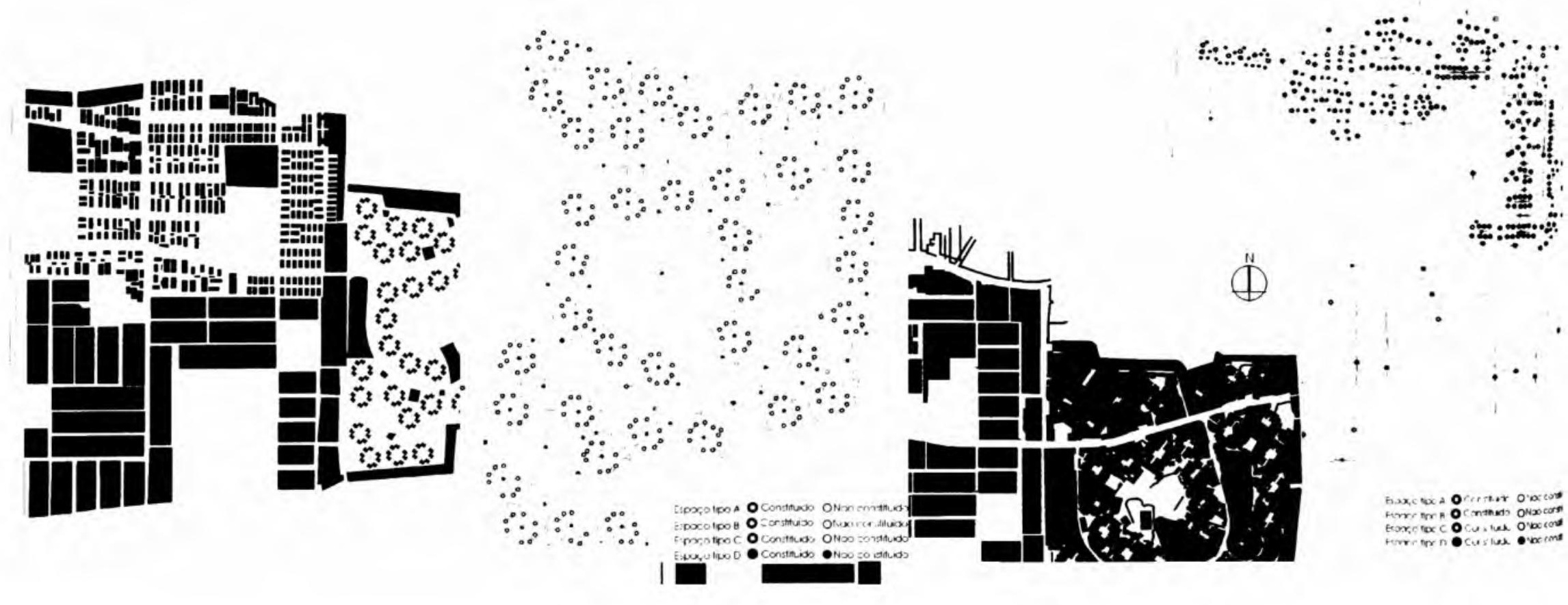


\section{Tipologia Espacial Como Uma Instância dos Layouts Urbanos}

Layouts urbanos são arranjos morfológicos nos quais, por meio de particulares associações dos elementos de composição urbana - edifícios e espaços abertos - é proposta uma certa estrutura, no sentido de que não apenas é precisa uma distribuição desses elementos de composição num território, mas e principalmente, os modos possíveis de relações entre diferentes localizações e de relações entre diferenças espaciais. As relações, definidas pelos graus de acessibilidade topológica, são partes essenciais para a compreensão das modalidades de apropriação social dos espaços urbanos. Aspectos como o controle espacial e a intensidade de utilização dos espaços, por atividades, pessoas ou veículos, são em grande parte condicionados pelos aspectos configuracionais do espaço urbano. (Hillier, B. et al,1993; Penn, A. et al, 1998).

Os estudos de layouts urbanos têm, tradicionalmente e por importantes razões, enfatizado as relaçōes mais globais, avaliando os graus de acessibilidade relativa entre os diversos espaços entre si, traduzidos em diferentes níveis de integração e de segregação espacial. A integração/ segregação sintática refere-se à distância - ou profundidade - topológica e não métrica, em termos do número mínimo de mudanças de direção - ou eixos - necessários para passar, de um espaço axial considerado, para qualquer outro e, no limite, para todos os espaços de um sistema. Espaços de maior integração são, portanto, aqueles que possuem uma menor profundidade em relação a todos os outros do sistema. São espaços que tendem a aproximar todos os outros. Ao contrário, os espaços de maior segregação são os menos acessíveis no conjunto considerado, mais profundos e, portanto, tendem a afastar todos os outros.

É bem trabalhada na literatura existente as relações entre níveis de integração espacial, a distribuição das atividades urbanas e a intensidade de movimento. Dessa forma, as atividades mais dependentes de grande movimento de pessoas para seu funcionamento tendem a se localizar em espaços de maior integração, já que são melhor acessados. Essas atividades, ou atratores, por sua vez, possuem um efeito multiplicador sobre o movimento e sobre a localização de outras atividades. Grandes atratores, como shopping centers, não apenas requerem localizações de fácil acesso geral, como produzem um impacto mais amplo sobre as áreas em que se localizam. Muitas vezes esses grandes atratores sāo produtores de acessibilidades resolvendo, a partir da reestruturação de suas proximidades, a inserçāo da nova função numa localização que apresente níveis de acessibilidade geral, incompatíveis com as necessidades impostas ao funcionamento desse atrator. 
A organização global de um assentamento fornece, portanto, um quadro bastante rigoroso das condições potenciais do ponto de vista das relações entre aspectos configuracionais do espaço urbano e as condições do seu uso social. A organização global, como mostra Hillier (1996), no entanto, é construída a partir da introdução de regras locais de crescimento do tecido, que produzem um padrão global para um determinado assentamento.

Diferenças locais, identidade, relações entre as partes, compreensão da forma e estrutura global estão intimamente associadas às propriedades locais do espaço urbano, da sua convexidade $^{1}$ e isovistass ${ }^{2}$ não se perdendo de vista a formiação do tecido urbano em seu conjunto. As peculiaridades dos espaços locais são função tanto das suas propriedades geométricas como dos tamanhos, proporções, etc.; relações com as barreiras que the delimitam, representadas pela presença ou não de constituições, isto é, dos pontos de interface entre o sistema público e o sistema privado; relações mais ou menos diretas etc.; e, principalmente, das suas características relacionais que permitem compreender onde estamos e para onde podemos ir no layout.

Uma observação detida dos aspectos relacionais permite perceber que as condições de uso, controle e apropriação dos espaços é função dos movimentos possíveis no e entre os espaços. Dessa forma, independentemente das particularidades geométricas, podemos identificar uma tipologia de espaços urbanos, conforme propõe Hillier (1996).

Pelo gráfico (Figura 1), em que é representado um sistema espacial qualquer, são registradas as relações que podem ocorrer entre os diversos espaços presentes neste sistema e podemos identificar os seguintes tipos de espaços:

a) espaços do tipo 'a' - são os que possuem apenas uma ligação com outro, em que não é possível ocorrer movimento através dele para outros espaços, apenas neles mesmos ou para eles mesmos. Como espaços sem saída, caracterizam-se por serem de ocupação e não de movimento;

b) espaços do tipo 'b' - possuem mais de uma ligação, fazem parte de esquemas em forma de árvore e estão no caminho de espaços do tipo 'a'. Assim, são partes necessárias de acesso a espaços do tipo 'a', mas também passagem obrigatória para o retorno desses espaços, o que os definem como de forte controle espacial;

(1) Convexidade refere-se à máxima extensāo bidimensional dos espaços urbanos de uso público, a partir da fragmentação do contínuo dos espaços públicos de um assentamento em subunidades de espaços convexos, possuindo a propriedade de, em qualquer ponto no seu interior, ser possível controlar e visualizar integralmente o que se passa neles. Para maiores detalhes, examinar em: HILLIER, B. \& HANSON, J. (1986); RIGATTI, D. (1997).

(2) Isovistas informam sobre o quanto de espaço público é visível e controlável, a partir de determinado espaço tido como referência. Constitui-se numa dimensão intermediária entre a convexidade e a axialidade mantendo, no entanto, sua função primordial de fornecer informaçōes localizadas do espaço urbano. Essa propriedade não será tratada neste trabalho, mas poderão ser obtidas maiores informações em: HANSON, J. (1998); HILLIER, B. (1996). 


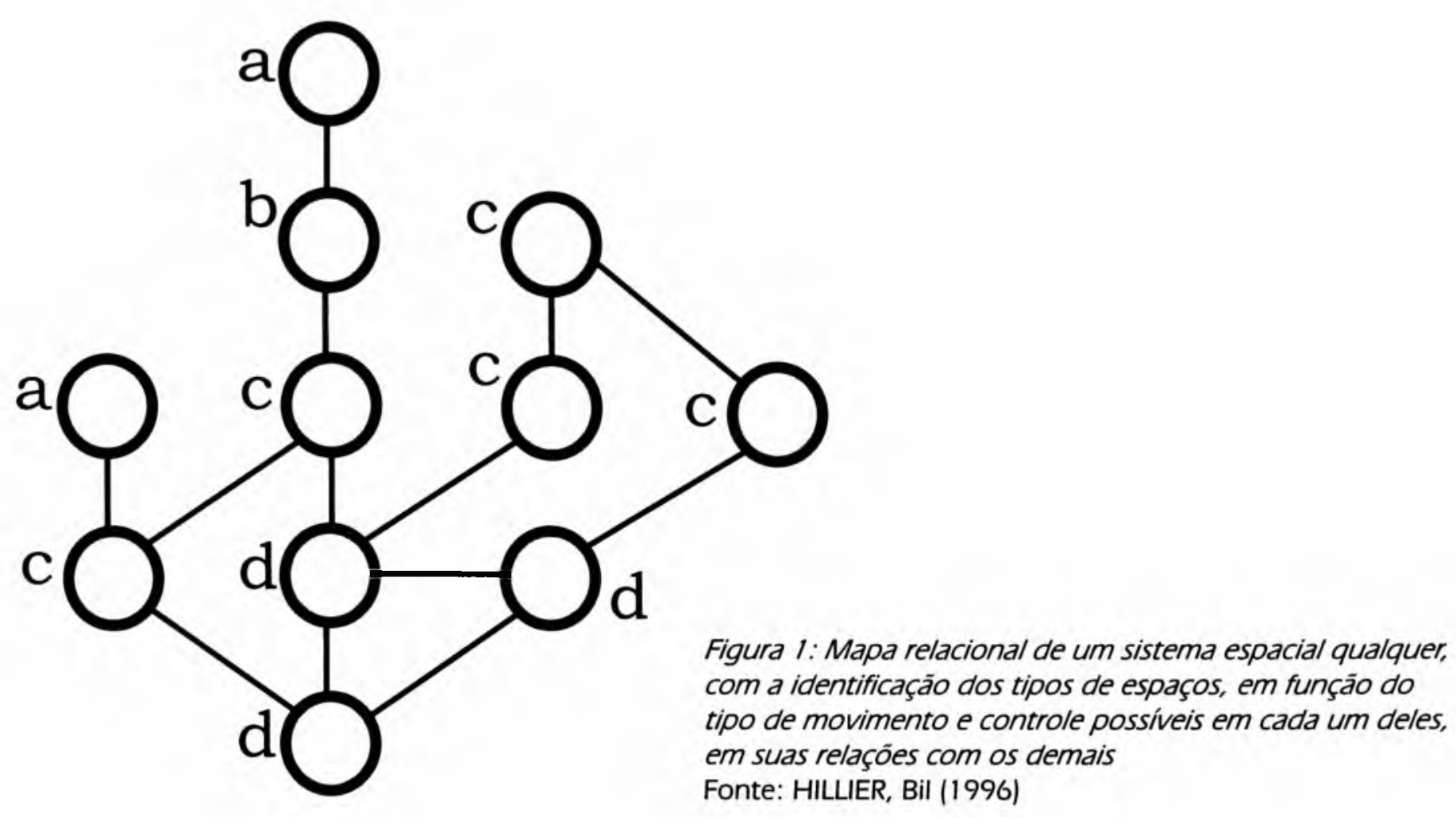

c) espaços do tipo ' $c$ ' - possuem mais de uma ligação com outros, fazem parte de um único anel em que não ocorrem espaços nem do tipo 'b' nem do tipo 'a'. Isto significa que, por este espaço, é possível selecionar rotas alternativas de movimento, mas dentro de uma seqüência de espaços definida. A importância desse tipo de espaço pode ser percebida pela observação de que algumas estruturas espaciais muito complexas necessitam utilizar seqüências espaciais como estratégia de solução. Pense-se, por exemplo, nos casos de estaçōes de metrô, onde a facilidade ou dificuldade em se acessar os pontos de embarque ou saída depende da existência de seqüências espaciais claras, com alternativas de percurso e movimento limitadas, caso contrário, tendem a tornar-se um labirinto de difícil compreensāo;

d) espaços do tipo 'd' - são os que possuem mais do que uma ligação no complexo em que não ocorrem espaços ' $a$ ' ou 'b' e que contenham, no mínimo, dois anéis com, no mínimo, um espaço comum a ambos. Dessa forma, ampliam-se as possibilidades de rotas alternativas para que se atinjam determinados espaços no interior de um sistema, sendo atratores naturais de movimento ${ }^{3}$ Para entender a importância dos espaços do tipo 'd' num complexo, se o espaço 'd' central for retirado da figura anterior, resta apenas uma seqüência única de espaços do tipo 'b', com alguns espaços do tipo 'a' em suas extremidades (Figura 2). Isso implica em limitações drásticas nas possibilidades de movimento e, ao mesmo tempo, uma reformulação das condiçōes de controle espacial viabilizado no interior do sistema.

(3) Esta questão é comentada em: HILLIER, B. (1996). 


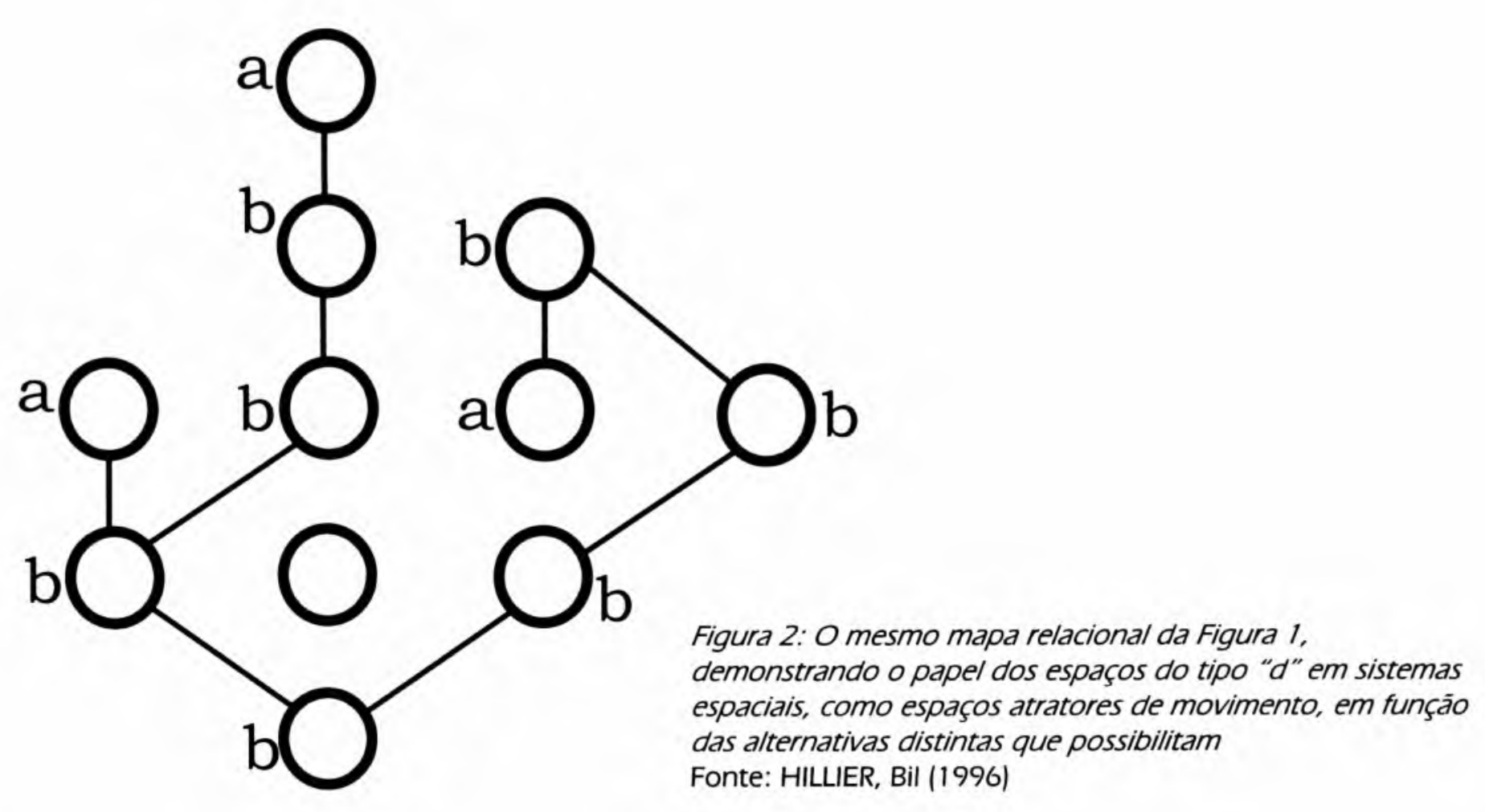

Para examinar um exemplo dos modos pelos quais os assentamentos são construídos a partir de propriedades locais, vejamos como estas particularidades se apresentam em dois conjuntos residenciais que, a partir da implantação dos projetos, apresentaram transformações espaciais significativas, implementadas individualmente por seus moradores: o Conjunto Rubem Berta ${ }^{4}$ - CRB - e o Conjunto Jardim Leopoldina - CJL, localizados em Porto Alegre/RS e construídos quase que simultaneamente entre o final da década de 70 e início da década de 80 (Figura 3).

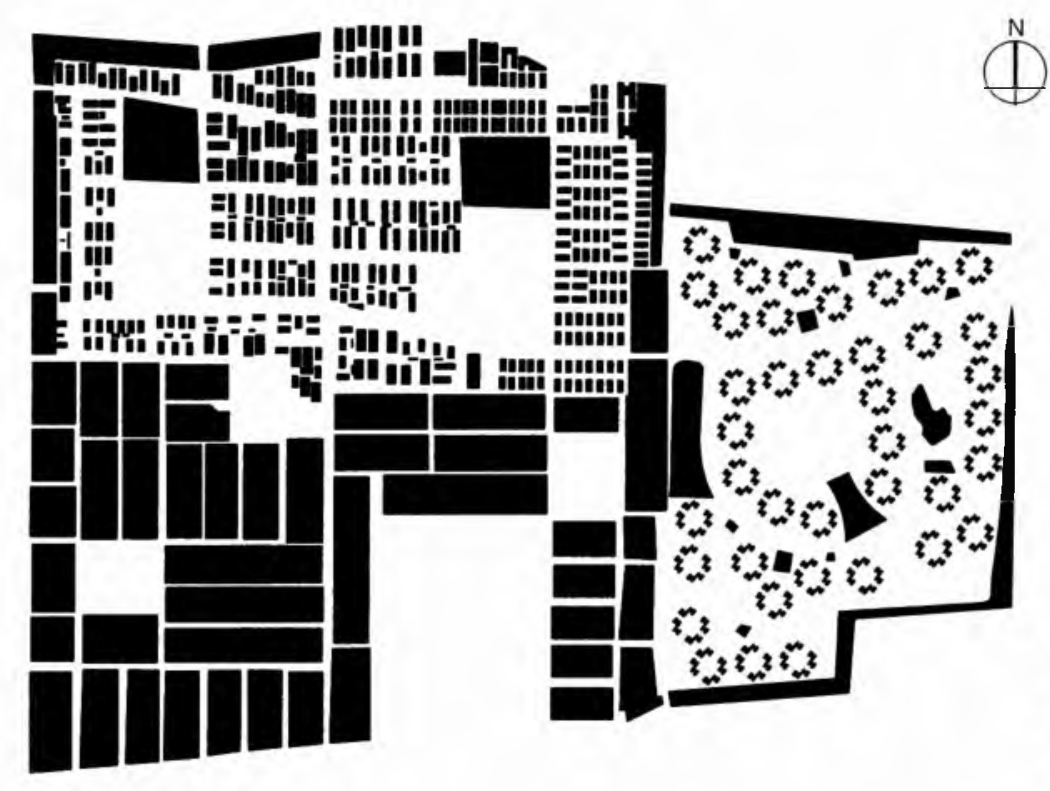

Figura 3: Mapa de figura e fundo dos projetos do Conjunto Rubem berta, à direita, e do Conjunto Jardim Leopoldina, à esquerda Fonte: Décio Rigatti

(4) Maiores detalhes sobre o Conjunto Rubem Berta: seu projeto, implantação e processo de transformação pelos moradores a partir de sua ocupação, ver em: RIGATTI, D. (1997).

186 \begin{tabular}{|l|}
$\begin{array}{l}\text { Paisagem } \\
\text { Ambiente } \\
\text { Ensaios } \\
13\end{array}$ \\
\cline { 2 - 2 }
\end{tabular}

São Paulo n. 13 p. 181199 dez. 2000 
No intuito de fornecer um breve quadro dos conjuntos analisados, fornecemos a seguir algumas informações básicas e algumas ilustrações dos processos de transformações mencionados.

\section{Quanto ao CRB}

a) O projeto implantado foi dimensionado para abrigar cerca de 20.000 pessoas em 4.992 unidades, distribuídas em 39 núcleos de quatro blocos de edifícios; cada um deles contendo 32 apartamentos, totalizando 128 por núcleo. Cada bloco é composto de 1 apartamento de 1 dormitório, 6 apartamentos de 2 dormitórios e 1 apartamento de 3 dormitórios em cada pavimento. Além das moradias, o projeto previa a instalação de uma série de serviços e equipamentos como escola, pequeno comércio, centro comunitário, centro de saúde, posto policial, o tratamento das áreas livres para lazer e recreação e a instalação de infra-estrutura de água, esgoto sanitário e energia elétrica;

b) Após uma ameaça de invasāo, a Cohab/RS decide convocar os titulares dos apartamentos do setor norte, compreendendo 10 núcleos, os quais são finalmente habitados no final de 1986. O restante do conjunto permanece com um ritmo lento de obras. Com a instabilidade gerada por essa situação de insegurança diante da conclusão do conjunto, em 21 de abril de 1987, os 29 núcleos inacabados são invadidos e todos seus apartamentos ocupados;

c) A saída dos invasores que não dispunham de recursos para assumir o financiamento junto à Cohab/RS deu origem a outro processo interno, vivenciado pelo conjunto, que é o da ocupação de áreas públicas destinadas pelo projeto como praças, playgrounds ou simplesmente áreas verdes, para a construção de moradias e pequeno comércio;

d) As intervenções efetuadas redefinem as relações dos blocos de cada núcleo com o espaço livre de edificaçōes, por um processo de privatização dos espaços abertos de uso público, assim destinados pelo projeto. Efetiva-se uma alteração radical nessa relação e os blocos são afastados do contato e escrutínio do espaço público, pela utilização de dois procedimentos básicos simultâneos: a construção de novas edificações, interpostas entre os blocos, e o novo espaço público; o cercamento e/ou muramento de áreas públicas;

e) A nova unidade espacial que surge é muito mais centrada na idéia do bloco em si do que propriamente no núcleo. Como base da ordem espacial do projeto, o núcleo é completamente destruído aqui. Os blocos agrupam-se entre si de diversas maneiras, com diferentes números de blocos agregados e de núcleos envolvidos, formando unidades espaciais distintas umas das outras e semelhantes a quarteirões tradicionais;

f) Em suma, as transformações espaciais verificadas para o geral do conjunto são baseadas: na redefinição espacial do espaço público e privado, tendendo à formação de espaços de transição semiprivativos no interior dos quarteirões; na geração de elementos novos construídos como garagens, moradias e pequeno comércio e serviço, com acesso efetuado 
tanto internamente ao quarteirão como diretamente pela via pública, sendo esta última modalidade utilizada em especial para abrigar moradia, comércio e serviço; na utilização de muros e cercas como elementos de separação do espaço externo e interno do quarteirão por onde ocorrem os novos acessos entre espaço público e espaços de transição para a entrada do edifício de habitação; na ampliação da área construída de unidades habitacionais localizadas no térreo dos blocos; na apropriação de porções do espaço público para a criação de pátios privativos de apartamentos térreos.

\section{Quanto ao CJL}

a) O projeto do conjunto compunha-se de dois setores distintos, de acordo com o tipo de moradias a serem construídas. Num setor, localizaram-se os edifícios de apartamentos. $O$ restante da área é destinada basicamente à habitação individual, na forma tradicional de quarteirōes com lotes individuais de cerca de $300 \mathrm{~m}^{2}$. Além da habitação e da área reservada a um parque - o Parque Chico Mendes -, compõem o projeto quatro áreas destinadas a escolas e três áreas destinadas a praças. A população total estimada para o empreendimento como um todo é de cerca de 38.100 pessoas distribuídas, aproximadamente, da seguinte maneira: 35.400 pessoas em apartamentos e 2.700 pessoas em residências unifamiliares;

b) O projeto da fase 1 data de 1979 e o da fase 2, de 1980. A primeira fase é concluída rápida e integralmente e a segunda fase nunca chegou a ser concluída, por falência da empresa responsável. Desta última fase, a maior parte da área destinada aos edifícios de apartamentos permanece desocupada e uma boa parte da área destinada a residências unifamiliares também. Todo o sistema viário do conjunto - excetuando-se uma via prevista no limite sul da gleba -, no entanto, é aberto, a infra-estrutura instalada e as vias pavimentadas;

c) Quanto ao processo de transformações espaciais implantadas pela população após a ocupação do conjunto, podemos identificar duas situações distintas: a relacionada com a habitação unifamiliar e a relacionada com a habitação multifamiliar. A área ocupada pela habitação unifamiliar no Jardim Leopoldina sofreu um processo de transformação física muito pequeno. De fato, o que se observa de alteração diz respeito fundamentalmente ao reforço na separação entre o terreno e o espaço público, por grades de segurança que são cada vez mais altas. As intervenções efetuadas no setor multifamiliar buscam, fundamentalmente, alterar a forma de relação dos edifícios com o espaço público, pelo uso de alguns mecanismos mais simples do que os adotados no Rubem Berta, muito devido às condições propostas pelo projeto. Dessa forma, como resultado básico, os blocos de apartamentos são afastados do contato direto com o espaço público. O mecanismo adotado é o do cercamento do alinhamento de frente, fazendo com que dessa medida resulte na formação, de fato, dos quarteirões indicados no projeto;

d) Neste processo, as transformações introduzidas com a finalidade de separar edifícios ou grupos de edifícios entre si se baseiam na utilização dos seguintes mecanismos: muros e

\begin{tabular}{l|llll} 
Paisagem & São Paulo n. 13 p. 181 & 199 & dez. 2000 \\
\cline { 2 - 3 } $\begin{array}{l}\text { Ambiente } \\
\text { Ensaios }\end{array}$ &
\end{tabular}




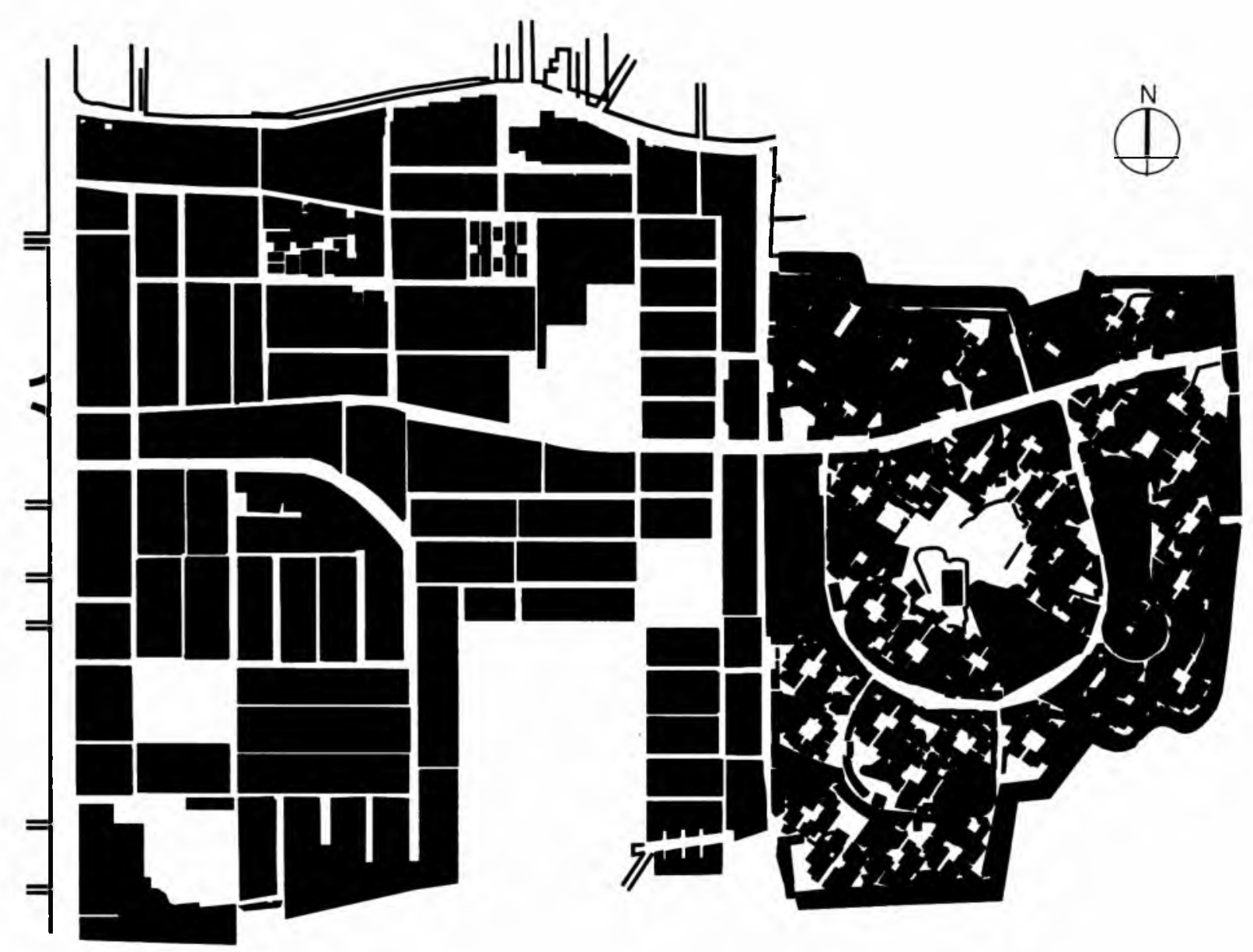

Figura 4: Mapa de figura e fundo da situação atual do Conjunto Rubem Berta, à direita, e o Conjunto Jardim Leopoldina, à esquerda Fonte: Décio Rigatti

cercas funcionando, às vezes, como elementos de reforço de condições de dificuldade referentes ao sítio; edificações, normalmente voltadas para necessidades individuais, como garagens para veículos ou destinadas ao uso coletivo do setor isolado, como churrasqueiras. Nesse particular, como no Rubem Berta, a interferência da população parece buscar a solução de algumas necessidades não resolvidas pela implantação do projeto. O que se percebe, em linhas gerais, no entanto, é que as transformaçōes introduzidas pela população não gerou, como no Rubem Berta, um processo de privatização do espaço público da mesma ordem (Figura 4);

e) Nos quarteirões da fase 2, no qual houve uma tentativa de alterar o esquema compositivo, utilizado na situação descrita acima, isto é, no qual a disposição dos edifícios não segue a mesma regra e os espaços livres são ampliados para receberem atividades não propostas para os demais quarteirōes já analisados, as transformações resultam mais difíceis e fragmentadas, à medida que, ao mesmo tempo em que os edifícios se agregam para formar novas unidades espaciais, de acordo com as disposições definidas pelos próprios moradores 
desses edifícios, há a necessidade de serem deixados espaços de uso público, isto é, servindo tanto aos moradores como aos estranhos do sistema, que possam servir de acesso aos equipamentos existentes no interior do quarteirão. O que se percebe, aqui, é que o tipo específico de solução proposta pelo projeto, ampliando as áreas livres e implantando as edificações de forma mais "solta" ou "livre" tornou as alterações mais difíceis e o resultado espacial mais fragmentado, com a geração de uma série de caminhos e becos, para pedestres, que se articulam ao sistema viário externo e ao mesmo tempo separam as unidades espaciais definidas pela intervenção da população (Figura 5).

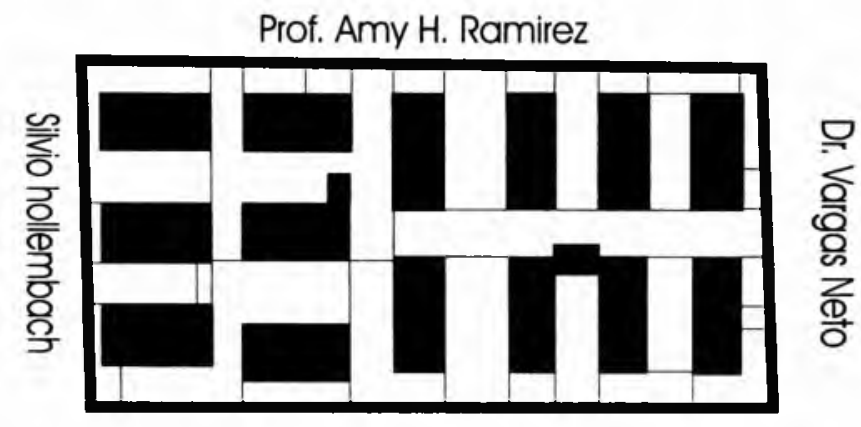

Dr. Aron Menda

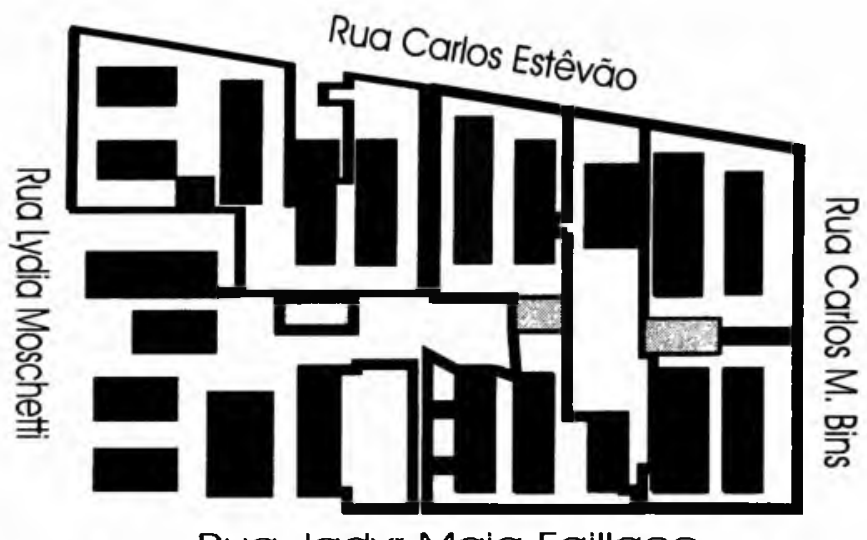

Rua Jadyr Maia Faillace

Edifícios residenciais

Comércio e serviço

Figura 5: Exemplos de modificações ocorridas em quarteirōes da la fase - à esquerda - e em quarteiröes da Za fase - à direita Fonte: Décio Rigatti

Após essa breve caracterização de aspectos básicos relativos aos dois conjuntos, retornemos ao nosso centro de interesse, qual seja, discutir, a partir dessas realidades concretas, algumas questões de caráter mais genérico e teórico relacionadas com a tipologia dos espaços públicos e suas implicações.

Para proceder a essa análise, foram elaborados os mapas relacionais dos dois conjuntos. Os mapas relacionais são representações dos espaços convexos e suas relações de adjacência, apresentando todas as relações possíveis de cada espaço com seus vizinhos e, no limite, com todos os outros do sistema avaliado. Essas representações permitem o exame das tipologias dos espaços públicos presentes nos sistemas espaciais em análise, bem como as relaçōes dos seus sistemas edificados com esses espaços, a partir da representação conjunta das transições ou interfaces entre espaços públicos e privados, denominadas de constituições.

Dessa forma, agregam-se, aos dados relativos à classificação tipológica dos diversos espaços convexos, as relaçōes de permeabilidade ou transições existentes entre o espaço público e os espaços privados - denominadas de constituiçōes - em cada um desses espaços. 
Examinando-se tanto as condições de projeto como a situação atual de cada um dos conjuntos temos, em síntese, o que segue (Figuras $6,7,8$ e 91 .

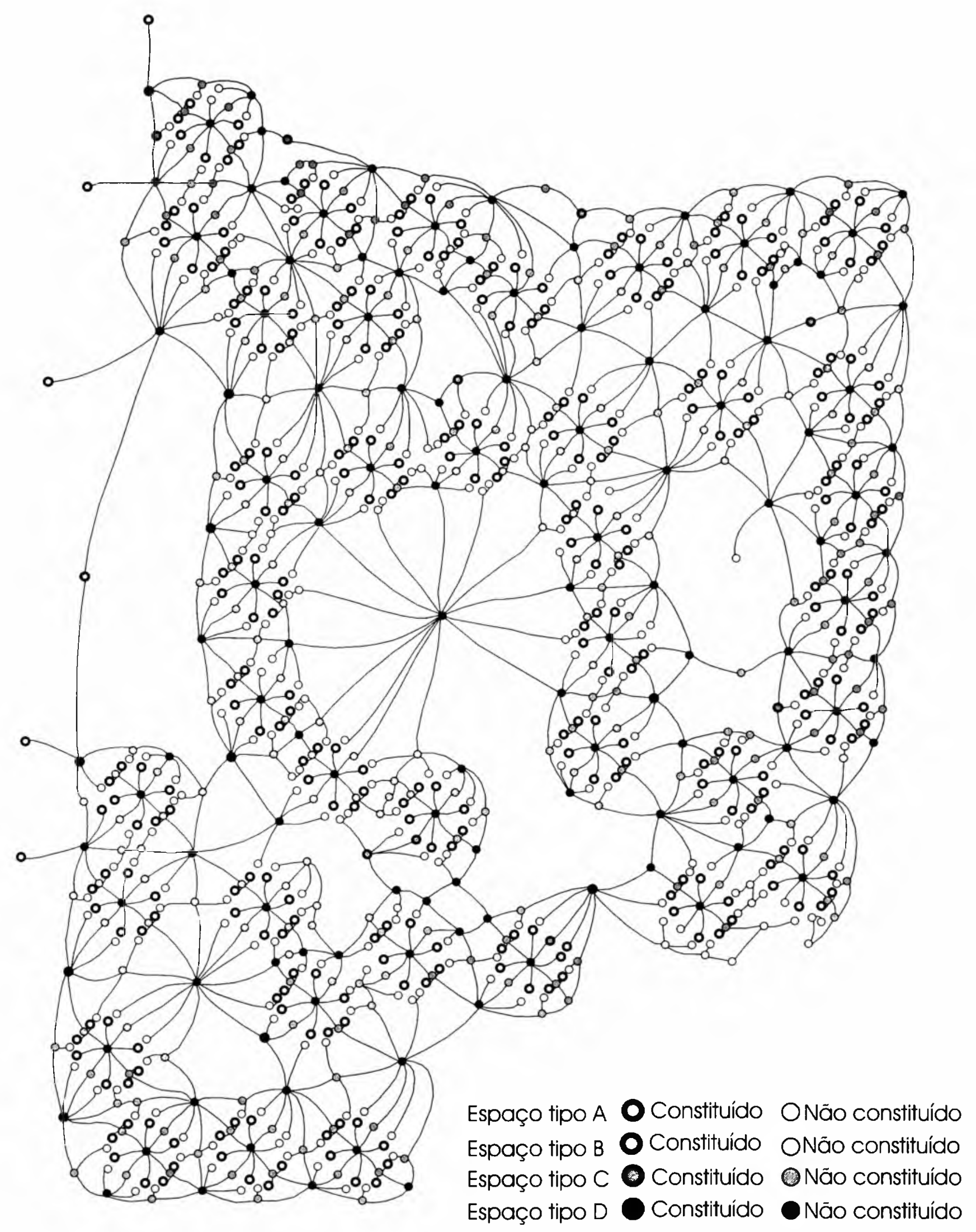

Figura 6: Mapa relacional da situação de projeto do Conjunto Rubem Berta Fonte: Décio Rigatti 


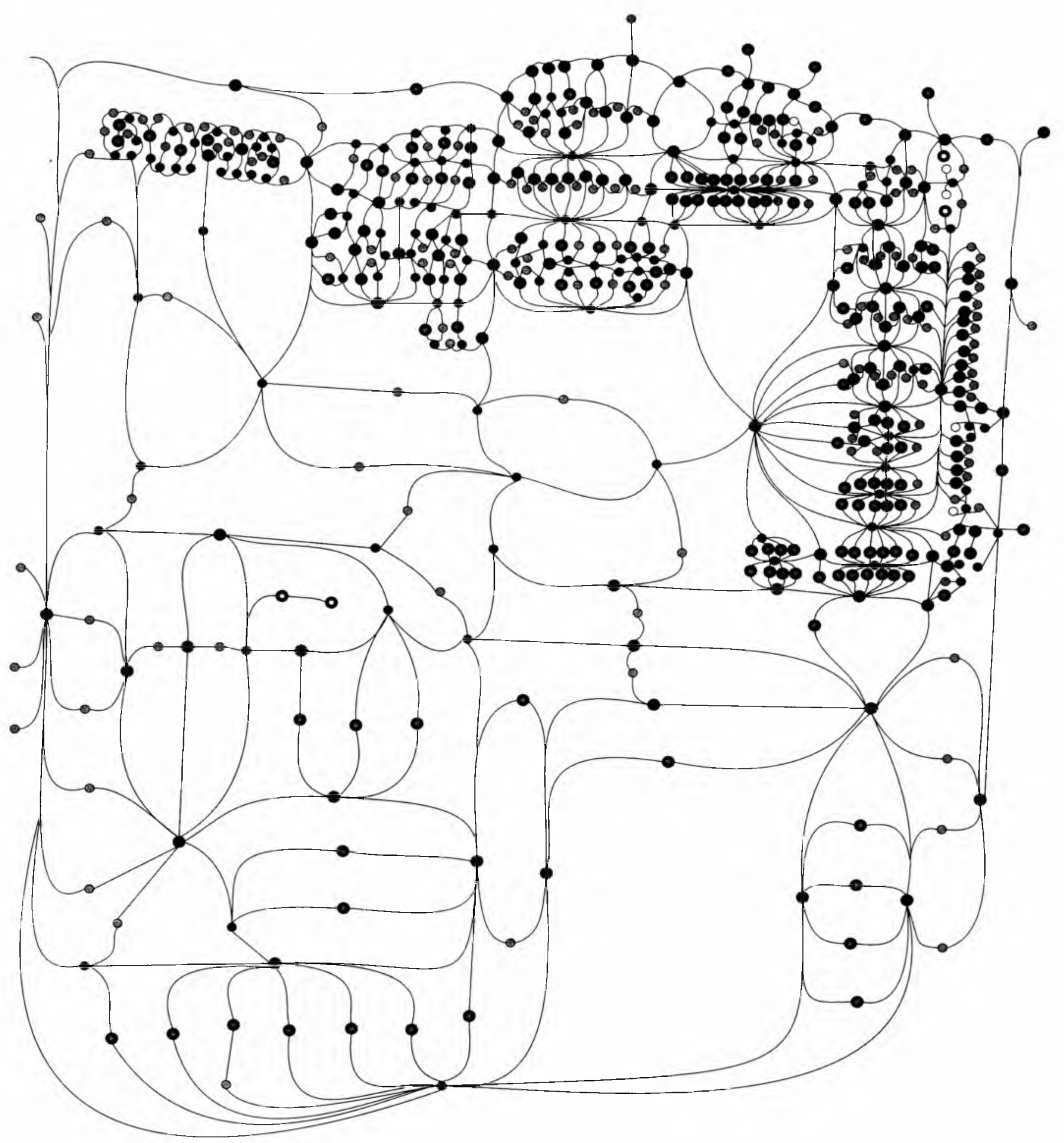

Espaço tipo A $O$ Constituído O Não constituído Espaço tipo B $O$ Constituido ONão constituído Espaço tipo C Constituído Não constituído Espaço tipo D Constituído Não constituído

Figura 7: Mapa relacional da situação de projeto do Conjunto Jardim Leopoldina Fonte: Décio Rigatti 


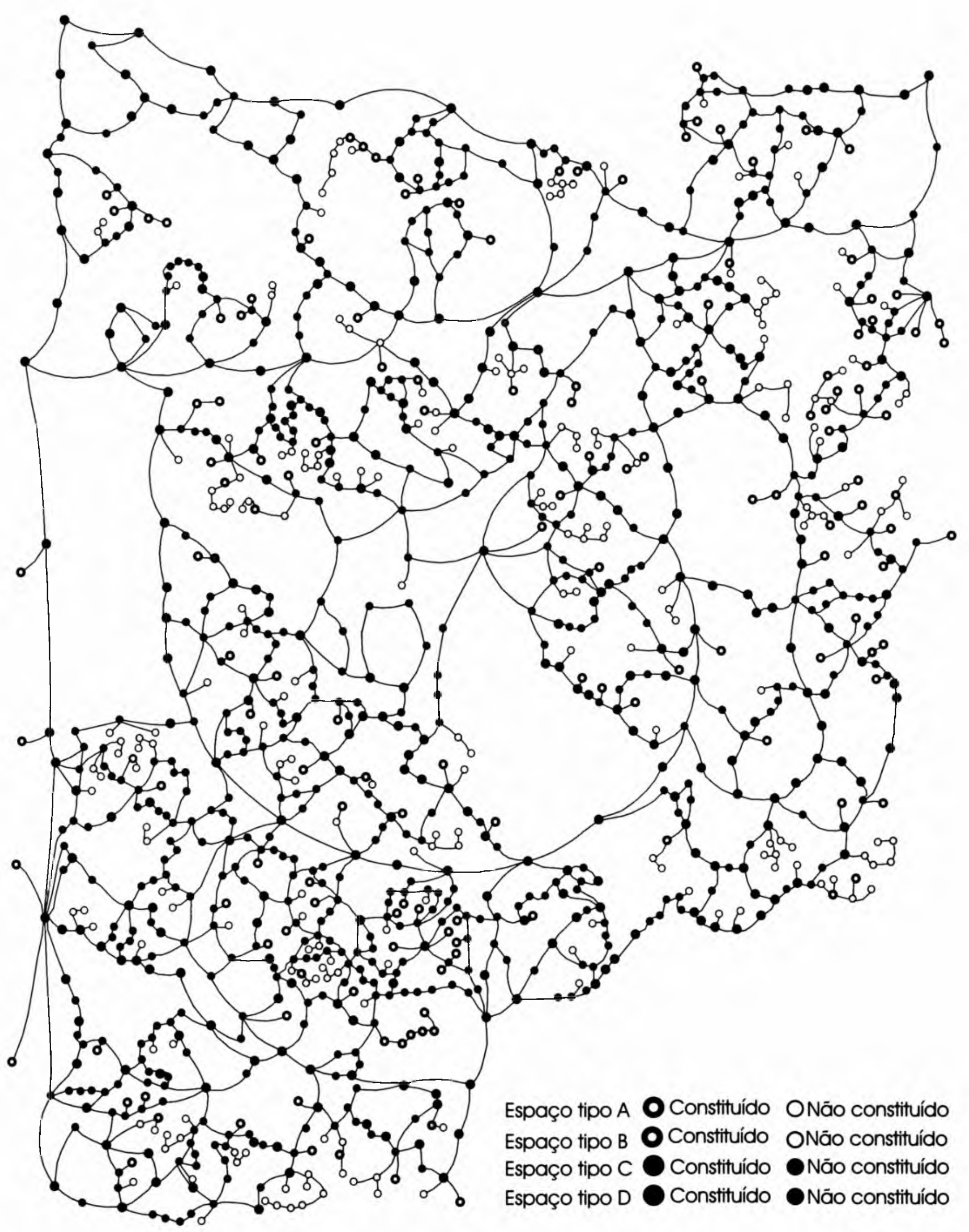

Figura 8: Mapa relacional da situação atual do conjunto Rubem Berta Fonte: Décio Rigatti 


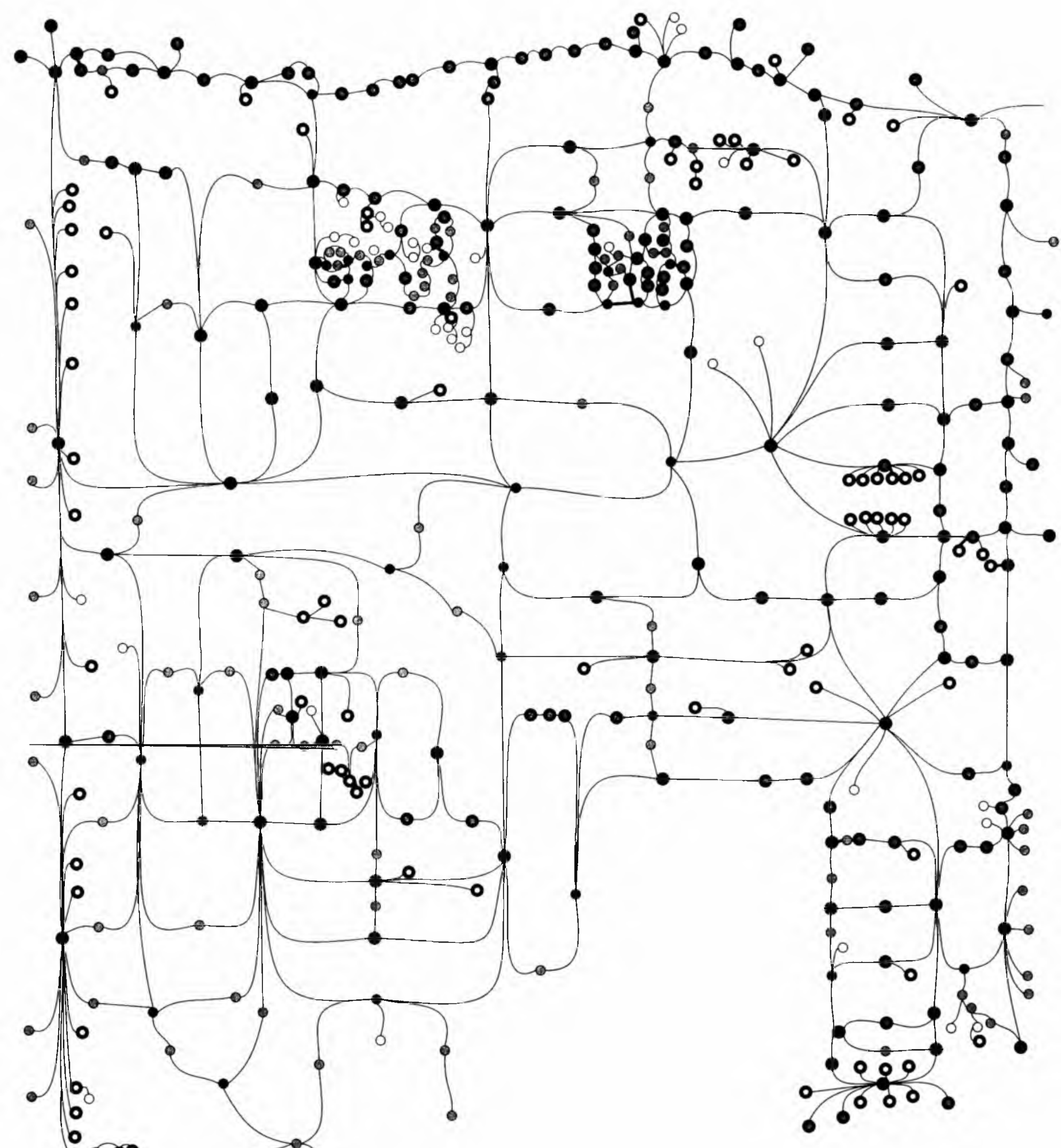

Espaço tipo A $\mathbf{O}$ Constituído ONão constituído Espaço tipo B O Constituído ONão constituído Espaço tipo $C$ Constituído Não constituído Espaço tipo D Constituído Não constituido

Figura 9: Mapa relacional da situação atual do Conjunto Jardim Leopoldina Fonte: Décio Rigatti 
No CRB, os espaços do tipo 'a' sofrem uma grande redução e chegam agora com praticamente $1 / 3$ do número previsto no projeto. Essa redução significa que a população não se utiliza de espaços do tipo sem saída, da mesma forma que ocorre na situação original, limitando a presença de espaços nos quais não é possivel o movimento através deles, mas apenas para eles, e privilegiando outros tipos de espaços para localizar as constituições, preferindo aqueles em que é possível o movimento através deles. Os espaços do tipo 'b' têm sua participação ampliada. De pouco mais de $1,7 \%$ dos casos previstos pelo projeto, passam a quase $9 \%$. A participação daqueles nos espaços constituídos passa de $0 \%$ para cerca de $6 \%$. Percebe-se que seqüências espaciais na forma de árvores são estratégias para definir formas mais amplas de controle sobre o movimento e a ocupação desses espaços. Os espaços do tipo ' $c$ ' passam a concentrar um pouco mais de $48 \%$ dos espaços. No entanto, a participação desse tipo nos espaços constituídos é sempre crescente, passando de apenas $1,82 \%$ no projeto para $43,23 \%$. Percebe-se que as alterações morfológicas privilegiam exatamente aqueles espaços que correspondem a uma maior possibilidade de movimento e ocupação espacial, já que possibilitam alternativas de percurso. Os espaços do tipo 'd' também são mais amplamente utilizados pela população do CRB. Originalmente respondendo por cerca de $13 \%$ dos casos, a participação desses é ampliada para $22,65 \%$. No que se refere à sua participação nos espaços constituídos, a mudança é mais dramática. Anteriormente respondiam por apenas 3,63\% dos casos, situando-se agora em $26,64 \%$. O que se nota é que a utilização desse tipo de espaço passa a ser - não apenas importante como modo de ampliar as formas de contato entre os diversos setores do sistema de maneira mais livre, dadas as alternativas de percursos geradas, mas também sua condição de atrator natural do movimento é valorizada pela sua constituição, via de regra correspondendo à implantação de atividades mais dependentes do movimento para o seu funcionamento.

Como resultado do processo de alterações morfológicas introduzidas pela população, a tipologia dos espaços do CRB é alterada, caracterizando-se pelas modificaçōes indicadas e comentadas a seguir:

a) ordem de freqüência dos espaços por tipo:

$$
\begin{aligned}
& \text { Projeto: } a>c>d>b \\
& \text { 1995: } c>d>a>b
\end{aligned}
$$

Fora os espaços do tipo 'b', sempre com participação menor, a evolução das transformações espaciais ocorridas no conjunto reduz o papel dos espaços que restringem as possibilidades de movimento e ocupação, como os do tipo 'a', e valoriza aqueles que possibilitam um maior número de alternativas e flexibilidade, como os espaços do tipo ' $c$ ' e ' $d$ '. Percebe-se que essas estratégias de transformaçōes conduzem à eliminação daqueles aspectos do projeto responsáveis pela maior rigidez no uso do espaço, principalmente por sua estrutura hierárquica em forma de árvore. A ampliação na utilização de espaços do tipo 'b' pode ser interpretada, basicamente, como uma maneira de promover a diferenciação espacial pelo reforço do controle espacial em determinadas situaçōes; 
b) ordem de freqüência de constituições por tipo de espaço:

Projeto: $a>d>c$

1995: $c>d>a>b$

Percebe-se que, em termos quantitativos, atualmente, a importância do tipo de espaços utilizados na nova morfologia do conjunto possui a mesma ordem do seu grau de constituição. Este parece ser um mecanismo pelo qual, gradualmente, a população corrige as incoerências do projeto. Isso significa que o grau de importância dos espaços, quanto às suas condições topológicas, é reforçado pela utilização de outras estratégias, como a sua constituição. O projeto lidava com esses aspectos de modo quase independente. A construção da nova morfologia encarrega-se de alterar as condições das relações dos espaços entre si e no conjunto, viabilizando condiçōes mais amplas e ao mesmo tempo mais flexíveis de movimento, uso e controle espacial.

No CJL, as transformações físicas implementadas pelos moradores produzem uma interessante mudança nessa propriedade. A excessiva concentração de espaços dos tipos 'c' e 'd', na situação de projeto, produz uma uniformidade espacial que se manifesta pela grande anelaridade do sistema, isto é, quase sempre se está em espaços pertencentes a um anel de percurso ou a dois ou mais, simultaneamente. Com isso, as condições de controle espacial ficam claramente uniformizadas, sem definir áreas em que predomina o controle dos moradores ${ }^{5}$ Como uma das estratégias para produzir uma maior diferenciação espacial no conjunto como um todo, a população introduz um maior número de espaços do tipo 'a', respondendo agora por praticamente $1 / 4$ do total de espaços e por mais de $27 \%$ daqueles constituídos. Os espaços do tipo 'b' também ampliam sua participação para um pouco mais $3 \%$, respondendo por quase $3 \%$ dos constituídos. Os espaços do tipo 'c' têm uma redução de mais de $8 \%$ e cerca de $12 \%$ quando consideramos os constituídos. Já o número de espaços do tipo 'd' passa de $46,34 \%$ do total, no projeto, para $29,34 \%$, na presente situação, com uma participação reduzida em $17 \%$. Considerando-se sua constituição, nota-se que esse tipo de espaço tem sua participação reduzida de $50,95 \%$, no projeto, para $33,46 \%$, na situação atual, com participação reduzida também em cerca de $17 \%$. O que se percebe das repercussōes das transformaçōes implementadas pelos moradores do conjunto, na formação de uma nova tipologia de espaços de controle e movimento, é que, além de gerar uma maior diferenciação espacial, a tipologia espacial é utilizada num sentido mais estrito, explorando as possibilidades de movimento e controle, e afetando a localização das atividades urbanas, de acordo com diferentes atributos e vantagens locacionais. Fazendo-se a mesma síntese feita para o CRB, a tipologia espacial no CJL apresenta a seguinte ordem:

(5) No limite, podemos pensar um sistema espacial de malha ortogonal regular, no qual a homogeneidade do controle espacial da grelha seria confirmada pela ocorrência, em números tendendo à igualdade, de apenas espaços do tipo ' $c$ ' e do tipo 'd', significando que, nessa malha, ou estamos numa esquina $e$ podemos escolher qualquer um dos anéis possíveis de movimento - espaço do tipo 'd', ou entre duas esquinas - espaço do tipo ' $c$ '.

Paisagem
Ambiente
Ensaios
13

São Paulo n. 13 p. 181199 dez. 2000 
a) ordem de freqüência dos espaços por tipo:

Projeto: $c>d>a>b$

Situação atual: $c>d>a>b$;

b) ordem de freqüência de constituiçōes por tipo de espaço:

Projeto: $d>c>a>b$

Situação atual: $c>d>a>b$.

Nota-se que, diferentemente do que foi feito no CRB, no CJL a ordem de freqüência dos espaços por tipo permanece a mesma, sendo alterada apenas a participação relativa de cada um deles. A mesma ordem é dada para a freqüência de constituições por tipo de espaço para a situação atual, alterando a seqüência definida pelo projeto. Dessa forma, mesmo a partir de pontos de partida muito opostos, o que se observa, para ambos os conjuntos, é que parecem existir algumas regras constantes nas transformações das morfologias físicas dos assentamentos, impressas pelos moradores, e que vão redundar em semelhanças do ponto de vista de como cada tipo de espaço é utilizado na construção dos sistemas em seu conjunto.

A questão da tipologia espacial, de como cada espaço relaciona-se com seus vizinhos e com os demais, como é alimentado ou não pelo sistema edificado, como favorece determinados tipos de controle, como permite estabelecer relações de continuidade maior ou menor no movimento das pessoas, parece ser uma importante estratégia de construção do espaço, no qual, a partir de regras locais, são definidas as condições de apropriação de todo o assentamento.

Mesmo de forma sucinta, o que se conclui do analisado acima é que, na construção do espaço urbano, as regras locais que definem a estrutura global utilizam-se da tipologia espacial como estratégia para a obtenção de layouts urbanos nos quais as diferenças espaciais são obtidas em dois níveis complementares. No global, pelas diferenças nos níveis de integração/ segregação. No local, pela diferenciação da tipologia dos espaços. Observa-se que, apesar de apresentarem trajetórias tão distintas, os dois conjuntos se encaminham para semelhanças no que se refere ao papel dos tipos de espaços na construçāo dos conjuntos. Essas semelhanças parecem ser de ordem genotípica, fornecendo uma importante pista para os projetos desse tipo de assentamento.

A característica básica dessas semelhanças pode ser resumida numa busca, por parte da população dos assentamentos e, nos casos estudados, com pontos de partida bastante diferentes, dadas as condições impostas pelos projetos, pelo rompimento ou de um excessivo enclausuramento do conjunto, como no CRB, ou, como no caso do CJL, da sua excessiva abertura para o exterior. Com isso, fica evidente que os moradores buscam um certo equilíbrio entre as relações mais globais do conjunto com o restante da cidade, e as relações mais locais, ou seja, as relações mais internas aos próprios conjuntos. $E$ isso, como se vê, é obtido pelas modalidades de transformações morfológicas implementadas, centradas na diferenciação nos níveis de integração/segregação espaciais, em termos mais globais, e nas transformações tipológicas dos espaços, em termos mais locais. 
No que se refere às relações entre tipologia e níveis de integração espacial ${ }^{6}$ vejamos algumas características apresentadas pelos projetos e pelas situações, após a intervenção da população.

No projeto do CRB, a opção de implantação gera uma distribuição da integração espacial tal, que não se nota uma clara relação entre os espaços de maior integração, a tipologia espacial, o nível de constituição espacial e a distribuição das funções urbanas. Dessa forma, algumas soluções, ao invés de se reforçarem mutuamente para consolidar a estrutura do conjunto, atuam em sentidos opostos. Assim, espaços com grande potencial para assumirem papéis de importância, do ponto de vista da localização das atividades não-residenciais, em função das condições de movimento e controle espaciais viabilizados, são tratados de forma indiferenciada e, com isto, as opções de projeto não confirmam as potencialidades por ele próprio geradas.

Já no projeto do CJL, dadas as condições de implantação adotadas, esses problemas comparecem de modo menos acentuado. As vias importantes que circundam o conjunto: avenidas Martim Felix Berta, Manoel Elias e Baltazar de Oliveira Garcia, como preexistências, são articuladas à área do projeto, de modo a tornarem-se canais de ingresso no conjunto, canais estes que possuem importância também sobre uma área mais ampla. A grelha bastante regular gerada pelo projeto faz com que os níveis de integração espacial sejam mais uniformemente distribuídos pelo sistema, reforçando a análise efetuada sobre os aspectos de tipologia espacial acima referidos. Isto é, a relativa uniformidade nos níveis de integração espacial produz um sistema de baixa diferenciação dos espaços entre si. O uso em larga escala de espaços dos tipos ' $c$ ' e 'd', associado à uniformidade dos graus de integração, ocorre em praticamente todo o assentamento, sem reforçar os espaços julgados mais importantes para a estruturação do conjunto.

Observa-se que o ocorrido após a intervenção da população, em ambos os conjuntos, é um processo paulatino de reforço de determinados espaços para a organização global e a manutenção de setores, articulados aos primeiros, que organizam o assentamento localmente.

Isso é obtido, como descrito, pela introdução de algumas regras locais, responsáveis pela reformulação da tipologia dos espaços dos conjuntos e que propõem uma nova estruturação global dos assentamentos, reforçada tanto pela própria tipologia espacial como na clara diferenciação dos níveis de integração espacial e pelo grau de constituição do tecido, conforme comentado anteriormente.

(6) A análise detalhada dos aspectos de integraçāo espacial dos dois conjuntos pode ser encontrada em RIGATTI, D. (1999). As condiçōes particulares do processo evolutivo do Conjunto Rubem Berta podem ser examinadas em RIGATTI, D. (1997).

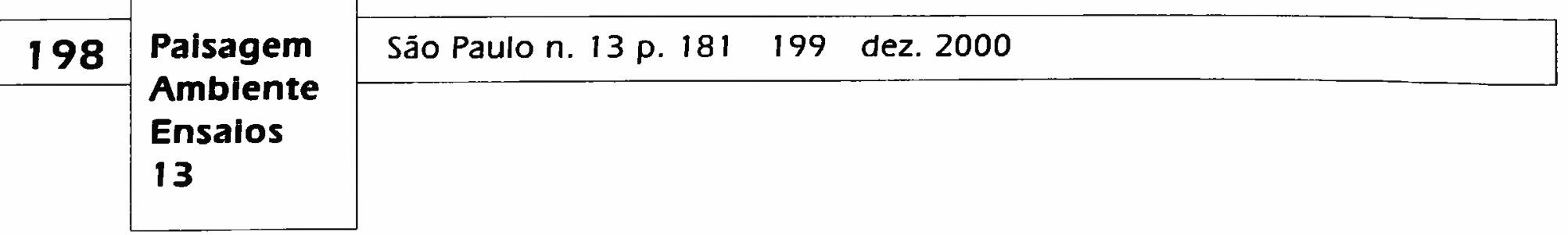


O que fica claro, pelos casos analisados, é que o projeto de assentamentos humanos, independentemente da finalidade a que se destinam, requer proposições que trabalhem, de forma articulada, propriedades globais e propriedades locais. O papel dos espaços, medido pelos seus níveis de integração/segregação, o grau de constituição e a tipologia dos espaços convexos, conforme o discutido, são aspectos relevantes para essa aproximação. Outra lição retirada dos casos avaliados é: mesmo a duras penas e com altos investimentos individuais, as incongruências dos projetos são de algum modo revertidas pela intervenção dos moradores. Assim, em boa medida, a transformação do espaço produzida pelos moradores na ocupação da cidade, antes de se constituir num processo patológico, pode ser descrita como um processo de ajuste entre aspectos da cultura espacial não-atendidas pelo projeto ou das incongruências e contradições por ele propostos.

\section{Bibliografia}

HANSON, J. Decoding homes and houses. Cambridge: Cambridge University Press, 1998.

HILLIER, B., HANSON, J. The social logic of space. Cambridge: Cambridge University Press, 1986.

HILLIER, B. et al. Natural movement: Or configuration and attraction in urban pedestrian movement. Environment and Planning B: Planning and Design, v. 20, p. 29-66, 1993.

HILLIER, B. Space is the machine. Cambridge: Cambridge University Press, 1996.

PENN, A. et al. Configurational modeling of urban movement networks. Environment and Planning B: Planning and Design, v. 25, p. 59-84, 1998.

RIGATTI, D. Do espaço projetado ao espaço vivido: Modelos de morfologia urbana no Conjunto Rubem Berta. São Paulo, 1997. Tese (Doutoradol - Faculdade de Arquitetura e Urbanismo, Universidade de São Paulo.

Habitação e espaço urbano em conjuntos habitacionais em Porto Alegre: Ordem e estrutura, projeto e uso - subtema espaço urbano. Relatório de pesquisa ao CNPq/UFRGS e FAPERGS. Porto Alegre.1999. 